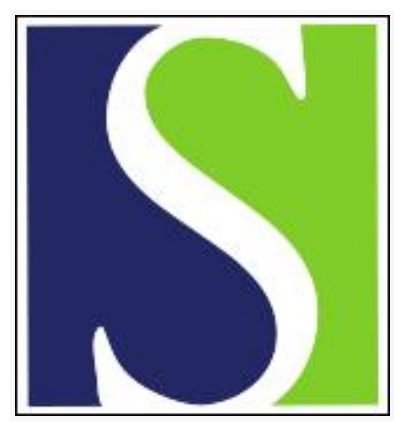

Scand J Work Environ Health 1987;13(6):524-526

https://doi.org/10.5271/sjweh.2006

Issue date: Dec 1987

Stomach cancer incidence in a cohort of fishermen in Singapore.

by Jeyaratnam J, Lee J, Lee HP, Phoon WO

Affiliation: Department of Community, Occupational and Family Medicine, Faculty of Medicine, National University of Singapore.

This article in PubMed: www.ncbi.nlm.nih.gov/pubmed/3433053

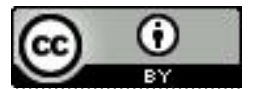




\title{
Stomach cancer incidence in a cohort of fishermen in Singapore
}

\author{
by Jeyarajah Jeyaratnam, MFOM, ${ }^{1}$ James Lee, PhD, ${ }^{1}$ Hin Peng Lee, MFCM, ${ }^{1}$ Wai On Phoon, FFOM ${ }^{2}$
}

\begin{abstract}
JEYARATNAM J, LEE J, LEE HP, PHOON WO. Stomach cancer incidence in a cohort of fishermen in Singapore. Scand J Work Environ Health 13 (1987) 524-526. A retrospective cohort study of 279 Chinese fishermen in Singapore was undertaken to examine the possibility of an elevated incidence of stomach cancer. The fishermen as a group had a greater than twofold excess in stomach cancer relative to Chinese men of similar age and over the same calendar years in Singapore, but the difference was not statistically significant. On further examination it was revealed that the four stomach cancer cases were observed among the subgroup of divers. The standardized incidence ratio for the divers was 4.3 , which was significantly greater than unity. There was no evidence of an increased risk for cancer of any other site (lung, nasopharynx and liver) in this cohort. Dietary factors are suggested as a possible explanation for the observation of an increased risk for stomach cancer among fishermen, but larger studies are required to test this hypothesis.
\end{abstract}

Key terms: epidemiology, modified life table, occupational cancer, standardized incidence ratio.

In Singapore stomach cancer ranks second on the list of cancers for men and fourth for women (20). In addition there is a high incidence of stomach cancer in Japan and other parts of Asia and South America, but in North America and Europe the incidence is low and is decreasing $(22,23)$. Studies indicate a reasonably consistent association between stomach cancer and various aspects of environment and life-style, particularly dietary intake. For instance, it has been documented that a decline in the incidence of stomach cancer has occurred over several generations among Japanese migrants to the United States, the indication being that environmental or life-style related factors are involved (12). Dietary factors such as salt intake in food (10), salted or preserved foods, and smoked foods $(3,7,9,11,24)$ and other personal habits (8) have been shown to be correlated with stomach cancer.

A relationship between occupation and stomach cancer is not well established. A slight excess risk for selected occupational groups such as miners $(5,14)$, asbestos workers $(6,19)$, rubber workers $(15)$, and metal product workers $(13,17)$ has been noted, however. These studies have suggested a possible link between stomach cancer and various factors in the work environment. None of these studies incriminated a possible dietary factor as being responsible for the observed association. The present study was initiated to examine the incidence of stomach cancer among diver fishermen in Singapore because of a clinical

1 Department of Community, Occupational and Family Medicine, Faculty of Medicine, National University of Singapore, Republic of Singapore.

2 National Occupational Health \& Safety Commission, Sydney, Australia.

Reprint requests to: Professor J Jeyaratnam, Department of Community, Occupational and Family Medicine, National University of Singapore, Lower Kent Ridge Road, Singapore 0511, Republic of Singapore. impression of one of the authors $(\mathrm{JJ})$ of an elevated incidence of stomach cancer among this group of workers.

\section{Materials and methods}

The study cohort comprised 320 Chinese registered as members of an association of fishermen in Singapore. These men fish (17) in the South China Sea and the Indian Ocean about 300 to $1500 \mathrm{~km}$ from Singapore. The subjects were registered as fishermen with the association during the period between 1947 and 1980, and the cohort was monitored until August 1985. The fishermen so identified were traced, and information was obtained on their age, date of commencement of work, duration of employment if no longer working as a fisherman, nature of work (diver or nondiver), and illnesses. Incidence data were obtained from the association register, medical records, and interviews of family members during the survey. The diagnoses for cancer were verified from the database of the Singapore Cancer Registry. Information was available on 279 ( 180 divers and 99 nondivers) of the 320 fishermen, the response rate being $87 \%$. The total personyears of follow-up was 3548 for the divers (average of 19.7 years per diver) and 2050 for the nondivers (average of 20.7 years per nondiver).

A modified life-table method (16) was employed in which person-years of observation were cumulated for each exposure duration in five-year age groups and five-year calendar intervals. These data were then used to generate expected numbers of site-specific cancer incidence cases based on the age and calendar-specific incidence rates of Chinese men in Singapore. The standardized incidence ratio (SIR) was computed as the ratio of the observed number of cases to the expected number of cases of site-specific cancer. Statistical significance for the SIR was determined under the assumption of a Poisson distribution for the observed 
number of cancer cases, as described by Bailar \& Ederer (1). All the statistical computations were performed with the man-years FORTRAN program (4).

\section{Results}

Table 1 shows the observed and expected numbers of stomach cancer among the fishermen and their corresponding SIR values. The SIR for all the subjects was 2.3. Thus the fishermen as a group had a greater than twofold increase in risk for stomach cancer relative to Chinese men of similar age and over the same calendar years in Singapore, but the SIR was not close to statistical significance ( $95 \%$ confidence interval 0.6-5.8). However, it is noteworthy that all four stomach cancer cases occurred among the divers, for an SIR of 4.3 , which was significantly greater than unity $(95 \%$ confidence interval $1.2-11.0)$.

All four stomach cancer cases occurred in men between the ages of 35 and 59 years. One case was identified within five years of the man becoming a fisherman, one between five and ten years, and two after more than ten years. As of August 1985, the mean age of the divers was 48.1 (SD 10.6) years, and that of the nondivers was 51.3 (SD 12.8) years.

In addition to the four stomach cancer cases, there were two cases of lung cancer, one of nasopharyngeal cancer, and one of liver cancer among the fishermen. The SIR of each cancer site for all the subjects was lower than unity, although the difference was not statistically significant. It was again noted that these cancers occurred only in the divers, but none of their SIR values was significantly in excess of unity.

\section{Discussion}

This study showed that Chinese fishermen in Singapore have a greater than twofold likelihood of developing stomach cancer in comparison to the corresponding general population. When this group was divided into divers and nondivers, it was observed that all of the stomach cancer cases occurred only among the divers, with a greater than fourfold risk relative to the general population (table 1). It is noteworthy that there was no evidence of an increased risk for cancer of other sites among this group of fishermen in comparison to the general population.

A possible explanation for the observation of a higher incidence of stomach cancer in this group could be associated with the known practice of these fishermen having an increased intake of salted fish or "rotted" fish or both in their diet. The process of salting fish increases the content of nitrates in the diet. Furthermore, this particular type of "rotted" fish could result in bacterial contamination of the stomach. The nitrates are subsequently reduced to nitrites and the bacterial flora could lead to the conversion of the nitrites to carcinogenic $\mathrm{N}$-nitroso compounds. A similar mechanism has been postulated for stomach cancer associated with iron deficiency and pernicious anemia $(2,18)$. In addition to this possible carcinogenic
Table 1. Stomach cancer incidence among Chinese fishermen grouped as divers and nondivers. $\mathrm{O}=$ observed cases, $E=$ expected cases, $S I R=$ standardized incidence ratio, $95 \% \mathrm{Cl}=$ confidence interval)

\begin{tabular}{lccccc}
\hline Fishermen & $\begin{array}{c}\text { Person-years } \\
\text { at risk }\end{array}$ & O & E & SIR & $95 \% \mathrm{Cl}$ \\
\hline Divers $(\mathrm{N}=180)$ & 3548 & 4 & 0.93 & 4.29 & $1.2-11.0$ \\
Nondivers $(\mathrm{N}=99)$ & 2050 & - & 0.84 & - & - \\
\hline Total $(\mathrm{N}=279)$ & 5598 & 4 & 1.77 & 2.25 & $0.6-5.8$ \\
\hline
\end{tabular}

mechanism, the situation is further aggravated by the fact that the fishermen's diet lacks fresh vegetables, a source of vitamin $\mathrm{A}(21,25)$. It has been recognized that the presence of vitamin $A$ in the diet may have a protective effect on the gastric mucosa and thereby may prevent the occurrence of stomach cancer.

The present study points toward an elevated incidence of stomach cancer for Chinese fishermen in Singapore, particularly among divers. The possibility of an associated dietary factor is considered a plausible explanation for the observation. We plan to investigate this possibility in the future by undertaking a comparative study of the dietary habits and life-style of fishermen and nonfishermen.

\section{References}

1. Bailar JC, Ederer F. Significance factors for the ratio of a poisson variable to its expectation. Biometrics 20 (1964) 639-643.

2. Broitman SA, Velez $\mathrm{H}$, Vitale $\mathrm{JJ}$. A possible role of iron deficiency in gastric cancer in Colombia. Adv Exp Med Biol 135 (1981) 155-181.

3. Choi NW, Entwistle DW, Michaluk W, Nelson N. Gastric cancer in icelanders in Manitoba. Isr J Med Sci 7 (1971) $1500-1508$.

4. Coleman M, Douglas A, Herman C, Peto J. Cohort study analysis with a FORTRAN computer program. Int J Epidemiol 15 (1986) 134-137.

5. Creagan ET, Hoover RM, Fraumeni JF. Mortality from stomach cancer in coal mining regions. Arch Environ Health 29 (1974) 28-30.

6. Enterline P, Decoufle P, Henderson V. Mortality in relation to occupational exposure in the asbestos industry. J Occup Med 14 (1972) 897-903.

7. Haenszel W, Kurichara M, Segi M, Lee RKC. Stomach cancer among Japanese in Hawaii. J Natl Cancer Inst 49 (1972) 969-988.

8. Hinds MW, Kolonel LN, Lee J, Hirohata T. Associations between cancer incidence and alcohol/cigarette consumption among five ethnic groups in Hawaii. $\mathrm{Br}$ J Cancer 41 (1980) 929-940.

9. Hirayama T. The epidemiology of cancer of the stomach in Japan with special reference to the role of diet. In: Harris RJC, ed. Proceedings of the 9th international cancer congress. Springer-Verlag, Berlin, Heidelberg, and New York 1967, pp 37-48. (UICC monograph series, vol 10).

10. Joosens JV, Geboers J. Nutrition and gastric cancer Proc Nutr Soc 40 (1981) 37-46.

11. Kolonel LN, Hankin JH, Lee J, Chu SY, Nomura A, Hinds MW. Nutrient intakes in relation to cancer incidence in Hawaii. Br J Cancer 44 (1981) 332-339.

12. Kolonel LN, Nomura A, Hirohata T, Haukin J, Hinds MW. Association of diet and place of birth with stomach cancer incidence in Hawaii Japanese and Caucasians. 
Am J Clin Nutr 34 (1981) 2478 - 2485.

13. Levin DL. Cancer rates and risks. Government Printing Office, Washington DC 1974. (DHEW publication no (NIH) 76-691).

14. Matalo NM, Klauber MR, Gorishek WM, Dixon JA. High incidence of gastric carcinoma in a coal mining region. Cancer 29 (1972) 733-737.

15. McMichael AJ, Andjelkovic DA, Tyroler HA. Cancer mortality among rubber workers. Ann NY Acad Sci 271 (1976) 125-142.

16. Monson RR. Occupational epidemiology. CRC Press, Boca Raton, FL 1980, pp 83-86.

17. Phoon WO, Wan WP, Boey HK, Chao TC. Health among fishermen-divers in Singapore. Proceedings of the 8th Asian conference in occupational health. Tokyo 1976, pp 263-267.

18. Ruddell WSJ, Bone KS, Hill MJ, Walters CL. Pathogenesis of gastric cancer in pernicious anaemia. Lancet 1 (1978) 521-523.

19. Selikoff IJ, Hammond EL, Churg J. Asbestos exposure smoking and neoplasia. J Am Med Assoc 204 (1968) 104-110.

20. Shanmugaratnam K, Lee HP, Day NE. Cancer incidence in Singapore 1968-1977. International Agency for Research on Cancer, Lyon 1983. (IARC scientific publication no 47).
21. Stehr PA, Gloninger MF, Kuller LH, Marsh GM, Radford EP, Weinberg GB. Dietary vitamin A deficiencies and stomach cancer. Am J of Epidemiol 121 (1985) $65-70$.

22. Stukonis MK. Cancer incidence cumulative raıes International comparison based on data from "Cancer Incidence in Five Continents." International Agency for Research on Cancer, Lyon 1978. (IARC technical report no $78 / 002$ ).

23. Waterhouse J, Muir C, Correa P, Powell J, ed. Cancer in five continents. Volume III. International Agency for Research on Cancer, Lyon 1976. (IARC scientific publications no 15 )

24. Weisberger JH, Raineri R. Dietary factors and the etiology of gastric cancer. Cancer Res 35 (1975) 3469-3474.

25. Weisburger JH, Reddy BS, Fiala ES, Wang YY, Vuolo LL, Wynder EL, Spingarn NE. Dietary factors in the causation and prevention of neoplasia. In: Burchenal $\mathrm{J}$, Oettgen $\mathrm{H}$, ed. Cancer: Achievements, challenges and prospects for the 1980 s. Volume 1 . Grune \& Stratton, New York, London, Toronto, Sydney and San Francisco 1981, pp $595-612$.

Received for publication: 20 March 1987 